\title{
A transdisciplinary research of coastal fisheries co-management: the case of the hairtail Trichiurus japonicus trolling line fishery around the Bungo Channel, Japan
}

\author{
Mitsutaku Makino ${ }^{1}$ Shingo Watari ${ }^{1} \cdot$ Taro Hirose $^{2,4} \cdot$ Kentaro Oda $^{2}$. \\ Masahito Hirota $^{1,2} \cdot$ Atsushi Takei $^{3,5} \cdot$ Michio Ogawa $^{2} \cdot$ Hiroshi Horikawa $^{3}$
}

Received: 31 January 2017 / Accepted: 26 June 2017 / Published online: 1 November 2017

(c) The Author(s) 2017. This article is an open access publication

\begin{abstract}
Under the coastal fisheries co-management regime in Japan, local fishers play important roles in deciding on and implementing local management measures. Therefore, using the case study of a hairtail trolling line fishery, we conducted a transdisciplinary research with fishers, processors, government officers, etc. Taking social and biological factors into account, we defined management criteria and targets (resource, economic, human community, and local food culture) in collaboration with local fishers. We chartered local fishing vessels to determine parameters that were easily understood by local fishers. We established a local consultative committee comprising fishers, processors, and distributors, and developed a fish distribution strategy to nurture the local hairtail food culture. The integrated
\end{abstract}

Electronic supplementary material The online version of this article (doi:10.1007/s12562-017-1141-x) contains supplementary material, which is available to authorized users.

Mitsutaku Makino
mmakino@affrc.go.jp
Shingo Watari
swatari@ affrc.go.jp
Taro Hirose
taro@affrc.go.jp
Kentaro Oda
oda@jamarc.go.jp
Masahito Hirota
mmhirota@affrc.go.jp
Atsushi Takei
atakei@affrc.go.jp
Michio Ogawa
ogawa@jacmarc.go.jp
Hiroshi Horikawa
yvonne_penghu@yahoo.co.jp

effects of various management scenarios were evaluated by the operating model. We found that co-ordinated management by both the trolling line fishery and purse seiners in the neighbouring prefecture was required to achieve targets. Two realistic scenarios are recommended: a conservative scenario that could achieve targets even with few strong year classes, and an adaptive scenario that protects strong year classes, but relies on a higher frequency of these. We shared these results with the local fishers and government officers, which led to actual improvements in management measures.

Keywords Operating model $\cdot$ Strong year classes · Adaptive management · Fish distribution · Food culture

1 National Research Institute of Fisheries Science, Japan Fisheries Research and Education Agency, 2-12-4, Fukuura, Kanazawa-ku, Yokohama, Kanagawa 236-8648, Japan

2 Present Address: Marine Fisheries Research and Development Center, Japan Fisheries Research and Education Agency, 15F Queen's Tower B, 2-3-3 Minatomirai, Nishi-ku, Yokohama, Kanagawa 220-6115, Japan

3 Japan Fisheries and Education Agency, 15F Queen's Tower B, 2-3-3 Minatomirai, Nishi-ku, Yokohama, Kanagawa 220-6115, Japan

4 Present Address: National Research Institute of Fisheries and Environment of Inland Sea, Japan Fisheries and Education Agency, 2-17-5, Maruishi, Hatsukaichi-shi, Hiroshima 739-0452, Japan

5 Present Address: All Japan Purse Seine Fisheries Association, 4F Daiichi Okana Building, 2-7-9 Toranomon, Minato-ku, Tokyo 105-0001, Japan 


\section{Introduction}

Coastal fishery is an important sector of Japanese fisheries. It harvests more than $40 \%$ of the total production volume, generating about $80 \%$ of the employment in the Japanese fisheries production sector. This employment provides the economic basis for more than 5000 fishing communities along the $35,000 \mathrm{~km}$ of Japanese coastline [1]. The wide range of species harvested all along the Japanese coast, from sub-arctic seas to the tropical seas, are the basis of a diverse local food culture in Japan. The majority of raw fish for sushi or sashimi are harvested by coastal fishers. The coastal fishery is an indispensable part of the traditional dietary culture of Japan (Washoku), which was designated an UNESCO Intangible Cultural Heritage in 2013.

Whereas offshore commercial fisheries are operated by large vessels, coastal fisheries are operated by a large number of small vessels using several types of gears targeting multiple species. Catches are landed at more than 3000 small fishing ports along the coastline. Therefore, topdown, command-and-control management measures by central government are both difficult and costly to implement. Consequently, a community-based fisheries co-management regime has developed in Japan [2-7]. Under this regime, responsibility and management are shared among resource users and the government. Therefore, it is difficult to introduce drastic management measures, even if the majority of fishers recognize that a particular resource is declining. More moderate measures are needed to allow fishing activity to continue while allowing resources to recover [8]. In this situation, one of the most important roles for fisheries scientists is in issuing timely alerts before a situation goes beyond a critical point, and to draft management plans that facilitate consensus building amongst resource users and managers. Such plans should consider not only resource and economic sustainability, but also community sustainability and local culture. In other words, coastal fisheries co-management is a multi-criteria decision-making process $[9,10]$. Therefore, it is inevitable that the type of research needed to facilitate such decision-making is multi-disciplinary and integrated fisheries research [11-15].

In this study, we developed an operating model for coastal fisheries co-management that assesses the integrated effects of various management scenarios. The model was applied to the trolling line fishery targeting hairtail Trichiurus japonicas at Usuki City, Oita Prefecture, Japan. This fish species has periodical occurrences of strong year classes, and such biological characteristics are clearly incorporated into the adaptive management strategy. We assessed several sets of management measures (i.e. management scenarios) that take into account various management criteria (i.e. resource sustainability, economic sustainability, community sustainability, and local food culture). Also, we disseminated the results of this study within the community to facilitate consensus building for better management. The main achievements so far and those predicted for the future are also briefly discussed.

There have been many studies on fisheries management using integrated bio-economic models [16-18]. Some of the latest studies have linked management strategies with spatial behaviour models to evaluate the movements of target species or fishers [19-21]. However, no previous studies have linked stochastic recruitment (in this study, the occurrence of strong year classes) to a seasonal adaptive management strategy for multiple fishery sectors, which is then linked to a local fish-distribution strategy.

Another feature of this study is its transdisciplinary approach [22, 23], which is promoted as the basic framework of the Future Earth Program [24]. Transdisciplinary research facilitates the integration of various traditional academic disciplines to solve serious real-world problems (i.e. integrated research [14]) and the involvement of wide-ranging stakeholders from outside academia in all the parts of the research (co-design, co-research and co-delivery). For example, in our project, the objectives' variables and their targets were defined in collaboration with local fishers. Local fishing vessels in the study area were chartered with the aim of determining parameters which could be both intuitively and easily understood by fishers. The fish distribution strategies were developed in consultation with the newly established local stakeholders' committee (fishers, fish processors, retailers and managers). The results of the analysis were shared with local stakeholders through a symposium and the operating model was handed over to the local government officers after a 2-day training course on how to use the model for local discussions. All these processes, as a part of transdisciplinary research, will enhance the legitimacy and the 'ownership' of the solutions by the local stakeholders, facilitate consensus building for co-management, and effectively lead to actual changes in management measures.

\section{Materials and methods}

\section{Usuki City and hairtail fishery}

Usuki City is at the mid-point of the Oita Prefecture coastline, located on Kyushu Island, in the western part of Japan (Fig. 1). In 2011, the total population of Usuki City was 41,082 , i.e. $8.8 \%$ lower than 10 years previously, while the national population had increased by $0.4 \%$ over the same period [25]. Decreasing populations are a common issue in rural Japan, while increasing populations are an issue in major Japanese cities like Tokyo. The main industries in Usuki City are traditional brewing (miso bean paste, soy sauce, distilled spirits), shipbuilding, tourism, agriculture, 
Fig. 1 Case study location

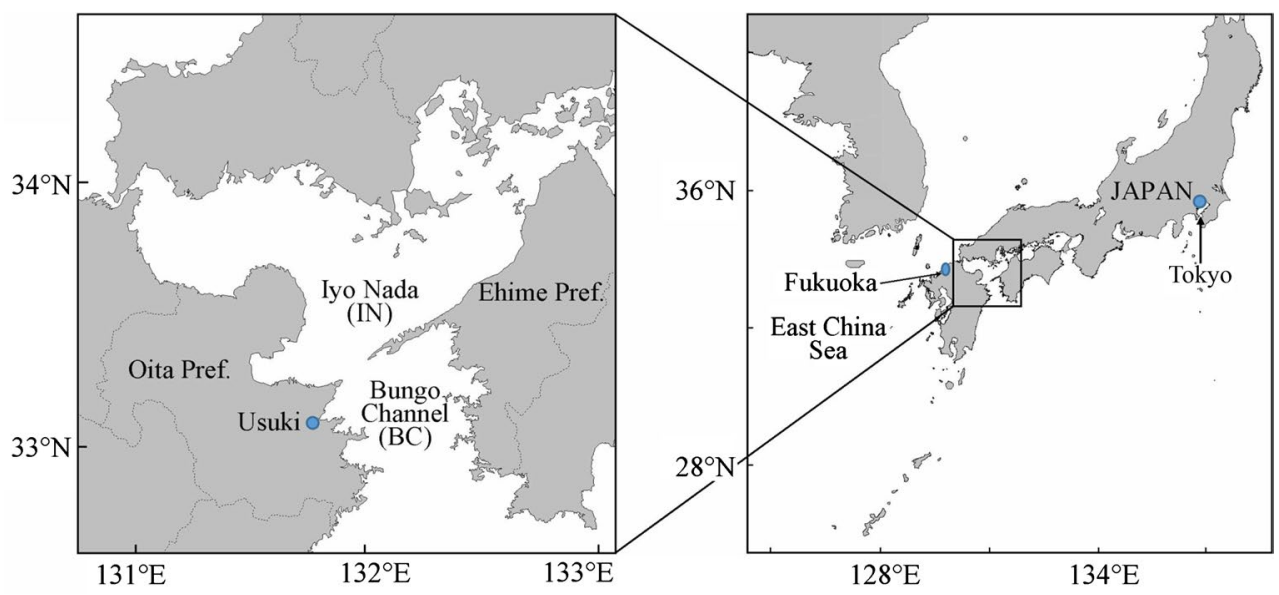

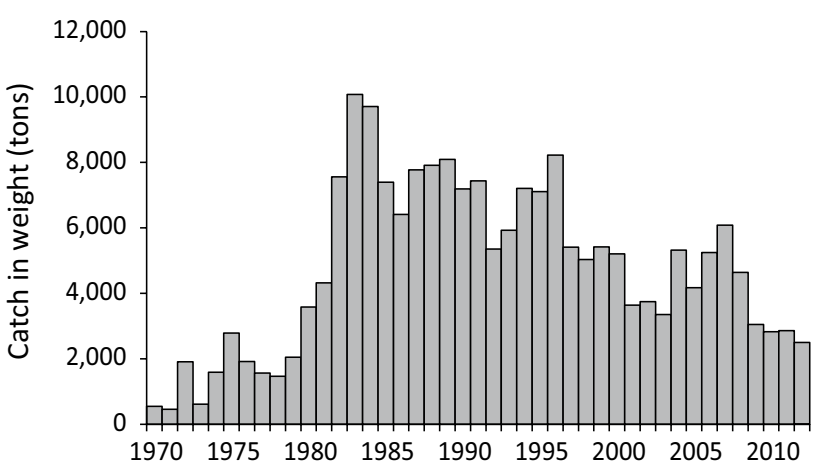

Fig. 2 Catches of hairtail around the Bungo Channel since 1970

and fisheries. Especially in coastal communities, the fishing industry is the main source of local jobs. Usuki City has 247 fishers who belong to the Usuki branch of the Oita Fisheries Cooperative Association (FCA). The number of Usuki fishers has decreased by $42 \%$ in the last 10 years, which is higher than the national average of a 30\% decrease. Almost all of them are small-scale fishers operating small vessels $(<5$ gross $t)$ around the Bungo Channel [26].

Usuki City is one of the main sites of high-quality hairtail production in Japan. Usuki fishers catch hairtail by trolling line, which was developed in this area in the 1980s; that is, it is relatively a new fishery (Fig. 2). In 2013, forty-five vessels (each $<5$ gross $t$ ) operated the hairtail trolling line fishery in Usuki. Almost all of them were couple operations, where husbands navigate the vessel and catch fish, and wives sort fish by size on board. About one-third of them operated the hairtail fishery year-round, while the others operated only in the high season (September-December) and engaged in other fisheries, such as the diving fishery. According to the hairtail landing record compiled by the Usuki branch of the Oita FCA in 2011, there was a total of 1260 vessel-days in the January-April season, 1329 vesseldays in the May-August season, and 1811 vessel-days in the
September-December season. The average number of operations per day was 9.0 (January-April), 9.7 (May-August), and 10.4 (September-December).

The estimated annual income for an average vessel in 2013 was about 5-6 million JPY/year, which is not enough to build a new vessel for a successor. As autonomous measures to conserve the hairtail resource, Usuki fishers have introduced various regulations for the fishing season, operation time, total number of baited hooks, and minimum size for landing. However, the stock is shared with purse seiners in the neighbouring prefecture, and the stock biomass (SB) is decreasing [27]. The purse seiners in the neighbouring prefectures have many alternative target species, so their economic dependence on hairtail is minor. Therefore, they have less interest in improving the hairtail stock level.

\section{Distribution and consumption}

The hairtail price in this area is set at the Fukuoka market, which is located in the biggest consumption area (Fukuoka City) in the northern part of Kyushu Island (Fig. 1). Almost all of the hairtail landed by Usuki fishers is transported cooperatively to the Fukuoka market. The Usuki branch of the Oita FCA developed this cooperative transportation system in 1995. First, the Usuki fishers sort hairtail by size and pack the fish along with ice and preservation film into $5-\mathrm{kg}$ boxes on board the vessel. The vessel identification symbol is written on the box for traceability and to display each fisher's responsibility. Transportation by trucks is shared with neighbouring fishers to save costs. As a result of these activities, the average price of Usuki hairtail is higher than that of hairtail from other areas in the Fukuoka market. In 2002, the Emperor's Prize was awarded to the Usuki branch for their advanced approach to better fish quality and cost saving.

Usuki fishers, however, know little about the downstream distribution of their catch to consumers. That is, they do not 
know who consumes the fish or how the fish are consumed. Therefore, to understand the full route of Usuki hairtail from the Fukuoka market to consumers, we conducted a survey of market staff, transporters, processors, and retailers [28]. We found that about $60 \%$ of Usuki hairtail is exported to Korea and $40 \%$ is distributed domestically in the western part of Japan. In the domestic market, large individual fish are consumed at premium restaurants or sold at department stores. Medium-sized hairtail are cut into fillets and sold at supermarkets and fish retail shops. Smaller ones are also sold at supermarkets or used as materials in processed foods. Therefore, we found that currently, there is almost no local consumption (LC) of hairtail within the Usuki area. To discuss this situation, we established the Local Consultative Committee for Hairtail Utilization in the Usuki Area (hereafter, the 'consultative committee'), and held nine meetings between August 2011 and March 2013. (The structure of the local consultative committee is summarized in Supplementary Table 1.) The consultative committee concluded that local hairtail consumption should be promoted to nurture the local food culture and to encourage consumers to better understand the local fishery, which should eventually lead to better fish prices and recruitment of new young fishers.

\section{Market demand and new local channels}

Tables 1 and 2 show the average price [Japanese yen (JPY) per 5-kg box] and the number of 5-kg boxes, respectively, transported from Usuki to the Fukuoka market in
2009-2013, grouped by season and size class. Table 1 also includes the approximate age span of each size class. Generally, the price is higher in the warmer months (May-August), and lower in the cooler months (September-December), which is the high season of the hairtail fishery. Also, the price of the mini-class (1.4-1.5 years old), which is the largest class by volume, is about one-third the price of the large class (1.9-2.3 years old), which is the second largest class by volume. Because hairtail is a rapidly growing species, in theory, the price of one mini-class hairtail will more than triple after 6 months if it is left to grow. On some market days in winter, the price of the mini-class is less than 1000 JPY/box. Therefore, from an economic point of view, the conservation of small hairtail individuals makes sense.

To understand the market and consumer demands for hairtail more precisely, we conducted a questionnaire survey on hairtail consumption and demand in Fukuoka and Oita Prefectures in February 2013. Details of the questionnaire contents and the participants are summarized in Supplementary Table 2 . We identified a steady market demand for fillets of medium- and large-class hairtail in summer [29]. Therefore, from a marketing point of view, a shift from catching smaller to larger individuals makes sense.

However, according to the biological nature of hairtail, strong year classes occur periodically. After the occurrence of a strong year class, some mini-class fish will be inevitably harvested even if local fishers try to protect them. Because the occurrence of a strong year class is a natural phenomenon, it should be considered in any management strategy.
Table 1 Average price of Usuki hairtail [Japanese yen (JPY) per 5-kg box] at Fukuoka market for 2009-2013, by size and season

Table 2 Average number of 5-kg boxes transported from Usuki to Fukuoka market for 2009-2013, by size and season

\begin{tabular}{lllll}
\hline Size class & Age (years) & January-April & May-August & $\begin{array}{l}\text { September- } \\
\text { December }\end{array}$ \\
\hline King (<8 individuals/5 kg) & $2.3-$ & 7461 & 8600 & 6329 \\
Large (9-12 individuals/5 kg) & $1.9-2.3$ & 5673 & 6036 & 4582 \\
Medium (13-16 individuals/5 kg) & $1.7-1.9$ & 3913 & 4315 & 3354 \\
Small (17-20 individuals/5 kg) & $1.5-1.7$ & 2928 & 3595 & 2320 \\
Mini (21-25 individuals/5 kg) & $1.4-1.5$ & 1890 & 2498 & 1393 \\
\hline
\end{tabular}

Transaction records were compiled by the Usuki branch of the Ohita Fisheries Cooperative Association (FCA)

\begin{tabular}{lcccr}
\hline Size class & January-April & May-August & $\begin{array}{l}\text { September- } \\
\text { December }\end{array}$ & Total \\
\hline King (<8 individuals/5 kg) & 1039 & 704 & 3925 & 5668 \\
Large (9-12 individuals/5 kg) & 4409 & 2821 & 8771 & 16,001 \\
Medium (13-16 individuals/5 kg) & 3493 & 1965 & 4742 & 10,200 \\
Small (17-20 individuals/5 kg) & 3889 & 2452 & 5633 & 11,974 \\
Mini (21-25 individuals/5 kg) & 4756 & 4412 & 8030 & 17,198 \\
Total & 17,586 & 12,354 & 31,101 & 61,041 \\
\hline
\end{tabular}

Transaction records compiled by the Usuki branch of the Ohita FCA 
Therefore, the consultative committee had intensive discussions on how to deal with this issue and in October 2012 concluded that mini-class hairtail should be utilized within the Usuki area to nurture the use of these in the local food culture. More precisely, the households of local fishers, local fish processors, tourism sectors, the Usuki branch of the Oita FCA, and local high schools cooperatively developed new recipes for value-added utilization of mini-class hairtail within the area. Some of them were consumed for lunch at local schools to educate the students about local fisheries. The city government officially supported these activities and organized press releases at the City Hall (Supplementary Fig. 1).

\section{Fishery system operating model}

Based on the situation described above, the main issues/ objective addressed in this study are as follows:

1. To ensure hairtail resource sustainability.

2. To continue the coastal fishery operation as one of the main economic activities in the local community.

3. To secure successors for this fishery.

4. To develop the local food culture.

To address these four inter-related issues, we needed the concept of a fisheries system that broadly covered resource dynamics, fisheries operations, and distribution and consumption of the landed fish in an integrated manner [14, 31]. Consequently, we developed the 'hairtail fishery system operating model' (Hairtail FSOM) which integrates the results from a resource dynamics model [27], a fishing selectivity model [32], economic calculations of the trolling line fishery operation, and hairtail distribution (Fig. 3). Using the Hairtail FSOM, we assessed the integrated effects of various management scenarios on the above four inter-related issues.

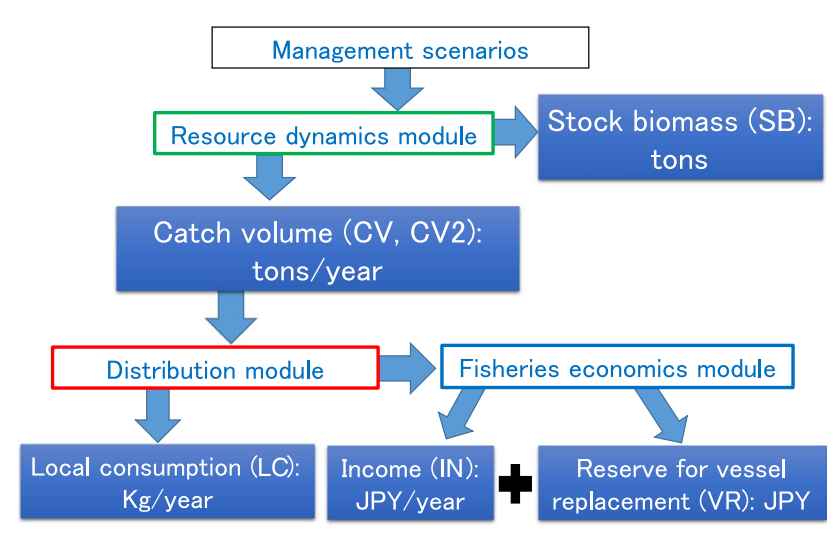

Fig. 3 Structure of the hairtail fisheries system operating model
For the four objectives of the hairtail FSOM, six variables were defined as follows. For objective 1, the resource sustainability, $\mathrm{SB}$, and catch volume $(\mathrm{CV})$ were calculated. As supplemental information, $\mathrm{CV}$ by purse seiners in the neighbouring prefecture targeting the same stock (CV2) was also calculated. For objective 2, the economics of the fisheries operation, and for objective 3 securing successors, we consulted with Usuki trolling line fishers. Their opinion was that it is equally important to have sufficient annual income to support a household with children and to have enough money to save for vessel replacement in the future. Therefore, we set the annual income (IN) and the accumulated savings for vessel replacement (VR) as the variables for objectives 2 and 3. In this study, we prioritized easily understandable variables for the objectives for discussion with Usuki fishers, rather than theoretical variables such as the expected economic rents for the fleet dynamics model analysis or the net present value calculation. As for objective 4 , i.e. local food culture development, we set LC as the objective variable.

Based on the past occurrences of strong year classes [25], $6000 \mathrm{t}$ was set as the target of SB. Similarly, based on the historical record, $250 \mathrm{t} /$ year was set as the target for CV. The average expenditure of a working household in Oita Prefecture was 4650 JPY when we consulted with Usuki fishers [33]. Therefore, 4650 JPY was set as the target IN. According to the survey of Usuki fishers, about 25 million JPY is required to build a new vessel for the hairtail trolling line fishery, so 25 million JPY was set as the target for VR. For LC, because the hairtail food culture has just begun to develop and there is insufficient processing capacity in the area, stable growth of the local distribution volume was set as a qualitative target. The simulation period was set at 25 years, based on the results of the survey of Usuki fishers and taking into account the generation time and the lifespan of the fishing vessels.

\section{Management scenarios}

Theoretically, there are many management measures that can be introduced for sustainable fisheries $[1,19,30]$. To achieve a resilient management regime, we need to develop a portfolio of several management measures that fit with the biological nature of hairtail as well as the socioeconomic issues relating to the trolling line fishery in the Usuki area [31].

Hairtail is a rapidly growing fish that has strong year classes periodically [27]. According to the price based on size (Table 1) and the market demand survey, it is sensible to preserve small fish and concentrate fishing pressure (FP) on larger fish. Another social characteristic is that the hairtail stock is shared between the trolling line fishers and 
purse seiners in the neighbouring prefecture. Therefore, we drafted combinations of the following management measures at various strengths (Table 3):

1. Protection of small hairtail by using larger bait.

2. Decrease in FP by restricting the number of operation days for trolling line fishers and purse seiners.

3. Protection of strong year classes by adaptively strengthening 1 and 2. The measures for local food culture development will be explained later in the distribution module.

Other autonomous measures which are already in place (length of fishing season, operation time, total number of baited hooks, minimum fish size) were kept constant. There are several reasons for this. First of all, the reduction of operation days can effectively reduce not only the FP but also the costs. Second, the existing minimum size limit $(25 \mathrm{~cm})$ is biologically reasonable because it corresponds to the mature length. Finally, under the Japanese fisheries management system, the total number of fishing vessels operating at sea is regulated by the vessel registration and fishing rights/license system (limited entry). Also, in Usuki, the decreasing number of fishers is a serious issue. Therefore, we assumed that the total number of trolling line vessels is fixed. In other words, we tried to create management scenarios that can sustain the current number of fishing vessels. Note that output controls such as total allowable catch (TAC) have been implemented for eight species (Pacific saury, walleye pollock, Japanese jack mackerel, Japanese sardine, chub mackerel, spotted chub mackerel, Japanese common squid, and snow crab) in Japan, but have not been implemented for hairtail. Therefore, we think that setting a TAC for hairtail is not a feasible and realistic scenario in the near future. However, the possibility of setting a TAC or individual quotas (IQs) for hairtail is discussed in the "Discussion".

\section{Modules of FSOM}

\section{Resource dynamics module}

Based on the models and data reported in Watari et al. [27] and Hirose et al. [32], the effects on SB and CV from the combination of (1) replacement of the bait, and (2) decreasing $\mathrm{FP}$, were calculated for 25 years in 4-month steps. As detailed in [32], the type-1 bait represents the status quo (all bait is live sand eel). In the type- 2 bait, all bait is replaced by big 6-inch lures. In the type-3 bait, half of the bait is 6-inch lures and half is live sand eel. The number of strong year classes and their timing (successive or discrete; sooner or later, etc.) strongly affected stock dynamics, so we included three to five strong year class occurrences, with randomly selected timing, in the calculations. As described above, FP is decreased by restricting the number of operation days at sea, and fishers will not agree with sudden and drastic decreases. Therefore, in this simulation, we assumed a maximum $20 \%$ decrease in FP. As for the adaptive protection of strong year classes, we assumed stronger levels of (1) and (2) in January-April immediately after the occurrence of strong year classes. The occurrence of strong year classes can be judged by fisheries officers in Oita Prefecture based on the catch structure during September-December and sampling surveys by the Oita Prefecture research vessel (Tokumitsu, personal communication).

\section{Distribution module}

The size classification rule in Table 1 (mini- to king-size classes) was applied to the catch composition data provided by the resource dynamics module, and the number of boxes was calculated by size classes and seasons, respectively. Then, the prices by size and season were multiplied to obtain the total landed value (JPY). As described earlier, based on the decisions made by the consultative committee in October 2012, a portion of cheap hairtail $(<2000 \mathrm{JPY} /$ box; i.e. miniclass hairtail in January-April and September-December) were assumed to be consumed within the Usuki area. On the other hand, the staff at the Usuki branch of Oita FCA believed that a certain amount of the catch should be distributed to the Fukuoka market, even in the cheap season, to maintain the reputation of the Usuki hairtail brand. Therefore, the following formula was applied to calculate the amount of LC. As indicated in the equation, the lower the market price, the greater the local distribution.

Ratio of local distribution $=(2000-$ Fukuoka Market Price $) / 1000$.

Table 3 Combination of measures in management scenarios

\begin{tabular}{|c|c|c|}
\hline 1. Protection of small hairtail by replacing rigs & $\begin{array}{l}\text { 2. Decreasing fishing pressure (FP) by limiting } \\
\text { number of fishing days }\end{array}$ & $\begin{array}{l}\text { 3. Protecting strong year classes by adaptively } \\
\text { strengthening } 1 \text { and } 2\end{array}$ \\
\hline ype 1 & & ved \\
\hline Type 2: all baits are 6 -inch lures & Decrease of FP in trolling line fishery only & Strengthen 1 and 2 in January-April season \\
\hline Type 3: combination of live bait and lures & $\begin{array}{l}\text { Decrease of FP in both trolling line fishery and } \\
\text { purse seiners in neighbouring prefecture }\end{array}$ & after observing strong year classes \\
\hline
\end{tabular}

The possibility of output control measures (e.g. total allowable catch, individual quotas) is examined in the "Discussion" 


\section{Fisheries economics module}

Based on the total landed value and the operation data collected by our chartered vessels, the revenue for a representative trolling line vessel operating year-round in Usuki was calculated. Then, based on the cost data collected from the chartered vessels (Table 4), the estimated annual income per representative vessel was calculated. The residual of substituting the average household expenditure in Oita Prefecture (4650,000 JPY) from annual income is accumulated for vessel replacement for a future successor (VR). Note that, because the interest rate at the major Japanese banks is about $0.02 \%$ year and the consumers price index is almost stable (1.6\% increase over the last 20 years [34]), we decided not to apply deflation to the residual but simply to calculate the sum. This made the calculations easy and intuitive to understand by the local fishers.

\section{Results}

We conducted simulations 1000 times at various strengths. The main results are summarized below. Also, Supplementary Table 2 summarizes the objective variables for the last 5 years of the simulation period.

\section{Management scenario 1: status quo}

Under the current situation, i.e. type-1 bait and no decrease in F, the FP is too strong, and strong year classes contribute to an increase in SB and CV only for several years. The majority of that increase is due to small individuals, meaning a low price. Under this scenario, all of the objective variables show decreasing trends, even when there are five strong year classes in the 25 years (Fig. $4 a$ ). It is clear that the current fisheries operations are not sustainable, and some additional measures are strongly required.

\section{Management scenario 2: type-2 bait and decrease in trolling line FP}

If type-2 bait is used to protect small individuals, and if the trolling line FP is decreased by $10 \%$, then three occurrences of strong year classes are required for success (Fig. 4b). However, the initial decreases in $\mathrm{CV}$ and annual income are too severe under this scenario, and if strong year classes do not occur in the first 5 years, the fishers will go bankrupt. We cannot obtain consensus for this scenario. Also, because the type- 2 bait hardly catches small individuals, the LC is low until the first strong year class occurs, which might result in a loss of momentum of the local hairtail food culture.

Table 4 Cost parameters

\begin{tabular}{|c|c|c|c|}
\hline & Cost item & Value & Details \\
\hline \multirow[t]{9}{*}{ Variable costs } & Fuel & $\begin{array}{l}24(1 / \text { day })+5 \text { (l/operation }) \times 105 \\
(\mathrm{JPY} / \mathrm{l})\end{array}$ & $\begin{array}{l}\text { Trip from port to fishing ground consumes } \\
241 \text { fuel; fishing operation consumes } 5 \\
1 \text { fuel }\end{array}$ \\
\hline & Engine oil & $0.7(1 /$ day $) \times 365(\mathrm{JPY} / \mathrm{l})$ & $\begin{array}{l}\text { Figure based on observations on chartered } \\
\text { vessel }\end{array}$ \\
\hline & Live bait & $\begin{array}{l}\text { Type-1: } 140 \text { (JPY/operation) } \\
\text { Type-2: } 0 \text { (JPY/operation) } \\
\text { Type-3: } 140 \text { (JPY/operation) }\end{array}$ & $\begin{array}{l}\text { All bait used in type- } 2 \text { are lures (no live } \\
\text { bait) }\end{array}$ \\
\hline & Replacement costs for bait & $\begin{array}{l}\text { Type-1: } 70 \text { (JPY/operation) } \\
\text { Type-2: } 130 \text { (JPY/operation) } \\
\text { Type-3: } 130 \text { (JPY/operation) }\end{array}$ & Type- 3 bait uses both lure and live bait \\
\hline & $5 \mathrm{~kg}$ fish box & $130(\mathrm{JPY} / \mathrm{box})$ & Provided by Usuki branch of Ohita FCA \\
\hline & Quality preservation film & 6.5 (JPY/box) & One roll (200 films) costs $1300 \mathrm{JPY}$ \\
\hline & Fukuoka market commission fee & $\begin{array}{l}\text { 4.95\% of Fukuoka market price } \\
(\mathrm{JPY})+61(\mathrm{JPY} / \mathrm{box})\end{array}$ & $\begin{array}{l}\text { Charges depend on market and its work- } \\
\text { ers + price of additional ice }\end{array}$ \\
\hline & Usuki branch commission fee & $\begin{array}{l}\text { [Fukuoka market price }(\mathrm{JPY})- \\
\text { Fukuoka market commission charges } \\
(\mathrm{JPY})] \times(8+2 \%)\end{array}$ & $\begin{array}{l}\text { Transportation fee }+ \text { charges by Usuki } \\
\text { branch }\end{array}$ \\
\hline & Commission fee for local distribution & $\begin{array}{l}\text { Local distribution price (3000 JPY/box) } \\
\times(2+7 \%)\end{array}$ & Charges by Usuki branch and its workers \\
\hline Fixed costs & $\begin{array}{l}\text { Vessel maintenance fees at dock, ves- } \\
\text { sel insurance fees, communication } \\
\text { charges, etc. }\end{array}$ & 734,878 (JPY/year) & Based on records of chartered vessels \\
\hline
\end{tabular}




\section{(a) Scenario 1}

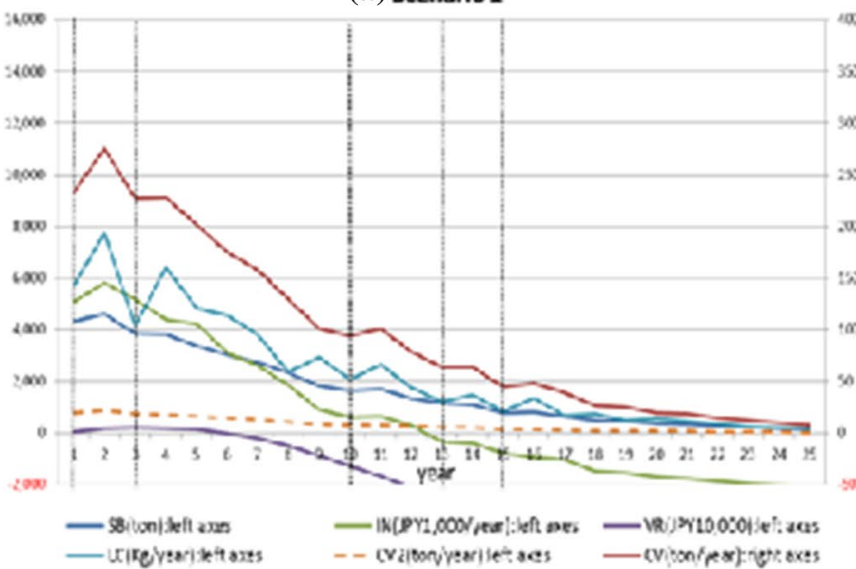

(c) Scenario 3

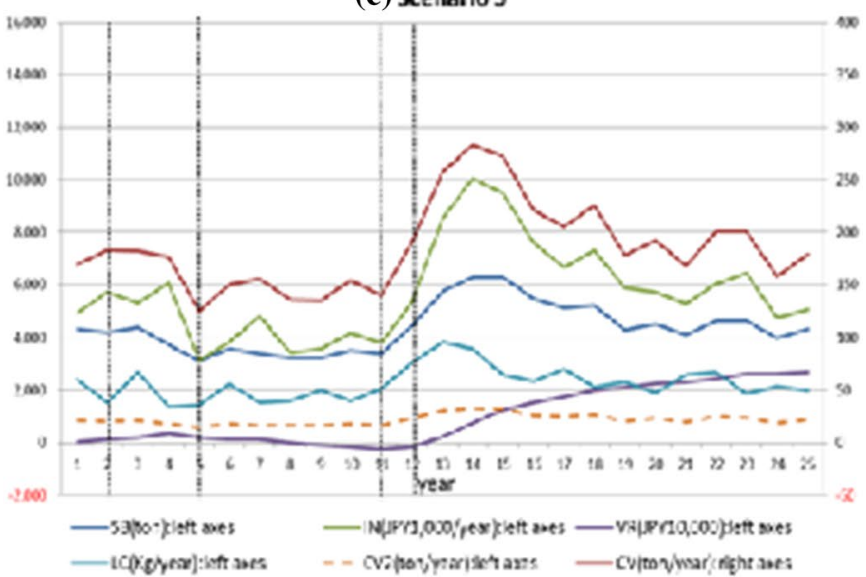

(e) Scenario 5

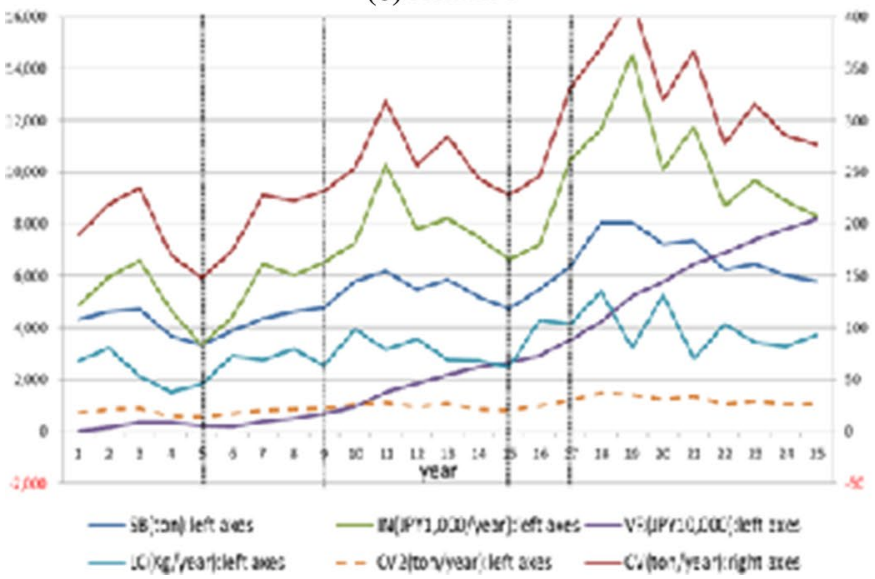

Fig. 4 Changes in six variables of objectives for typical simulation results from scenarios 1-5. Dotted vertical line shows the occurrences of strong year classes. SB target is $6000 \mathrm{t} /$ year. CV target by troll-

\section{(b) Scenario 2}

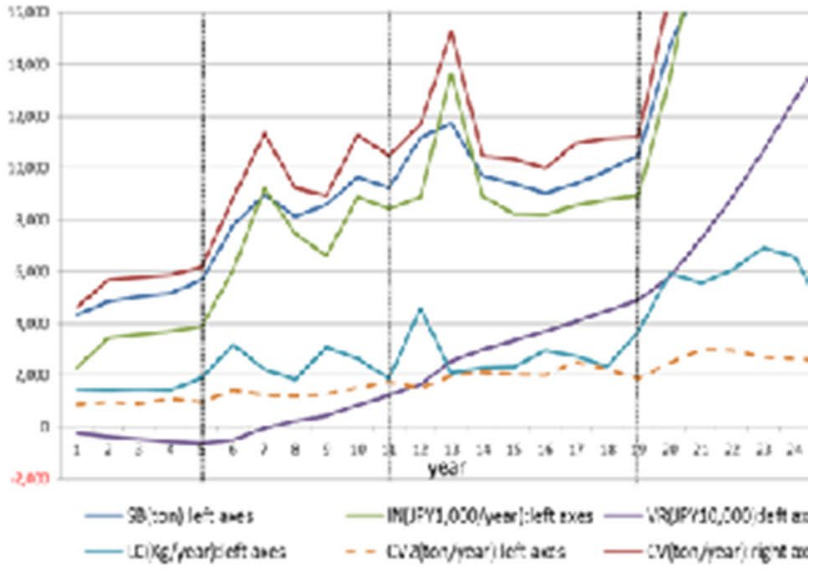

(d) Scenario 4

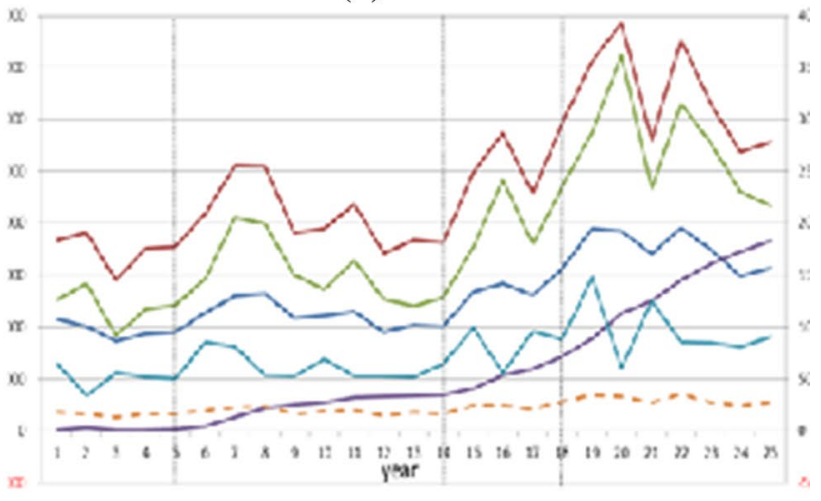

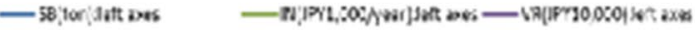

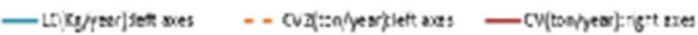

ing line fishers is $250 \mathrm{t} /$ year. CV2 target is $950 \mathrm{t} / \mathrm{year}$. IN target is 4650,000 JPY/year. VR target is 25,000,000 JPY/year. LC (kg/year) qualitative target is stable growth. For abbreviations, see Fig. 3 


\section{Management scenario 3: type-3 bait and decrease in trolling line FP}

If type- 3 bait is used, the size-selectivity effects are more moderate. However, to achieve the targets, the maximum decrease in trolling line FP (20\%) should be applied. Then, the probability of achieving targets is about $50 \%$ if there are four occurrences of a strong year class within 25 years. Also, as in management scenario 2, the initial decreases in $\mathrm{CV}$ and annual income are too severe to obtain consensus among fishers (Fig. 4c).

\section{Management scenario 4: type-3 bait and decrease in FP of both trolling line and purse seine fisheries}

If both the trolling line and the purse seiner fisheries can cooperate together to decrease FP by $15 \%$, then type- 3 bait can be used and three occurrences of a strong year class are sufficient to reach the targets. The initial decreases in annual income and CV are severe, but the situation will improve within 10 years or after the occurrence of the first strong year class (Fig. 4d).

\section{Management scenario 5: adaptive management to protect strong year classes}

Adaptive protection of strong year classes can reduce the initial decreases in annual income and CV and effectively protect small individuals. An example is to use type- 3 bait in the trolling line and decrease the FP of both fisheries by $10 \%$, and wait for the occurrence of a strong year class. When a strong year class occurs, both fisheries decrease FP by an additional 10\% and the trolling line will use only type- 2 bait in the following January-April period. Then, four occurrences of strong year classes will be required for successful results without severe initial decreases in CV and annual income. Also, because type- 2 bait avoids the catching of small individuals only in strong year classes, the LC is more stable than in other scenarios, which is a good situation for local processors and distributers (Fig. 4e).

\section{Discussion}

As a transdisciplinary study, we obtained several results which would not have been achieved by conventional approaches. First, we could effectively integrate various academic disciplines to discuss real-world issues. Researchers in biology, resource dynamics, gear selectivity, fisheries economics, food processing and distribution, marketing, etc., all worked together and constructed the Hairtail FSOM. Secondly, there were repeated communications and discussions between ourselves and local stakeholders (fishers, processors, distributers, retailers, tourism sector, local government officers, local research institute, local high school, etc.), which delivered new ideas. For example, the adaptive distribution strategy of small individuals, or new recipes for the development of the local food culture, are from such discussions with local stakeholders. Finally, the involvement of local stakeholders enhanced the legitimacy and ownership of the results, which finally led to the actual improvements in the management measures. During this process, we believe our project contributed to the capacity of local stakeholders, especially the young government officers, young FCA staff, and highschool students, to solve real-world issues based on the best available science.

The results of this study showed that management strategies targeting only the trolling line fishery (management scenarios 1,2, and 3) are insufficient to meet targets, because more hairtail are landed by purse seiners in the neighbouring prefecture than by trolling line fishers. Of course, it is difficult to coordinate the management measures across different gear types and prefectures, but as Fig. 4a shows, the catch by purse seiners should also decrease if both types of fisheries continue their current operations. A consensus between the trolling line and purse seine fishers is strongly recommended, as is the implementation of scenario 4 or 5 . The national government should take the leading role in this multi-prefectural coordination.

Both scenario 4 and 5 have merits and demerits. Scenario 4 with a 15\% decrease in FP will be successful even if there are only three occurrences of a strong year class in 25 years. This is the main advantage of this scenario. However, there are initial decreases in annual income and CV under this scenario, so it may be difficult to achieve a consensus, especially with young fishers supporting children. Also, after strong year classes occur, there will be a temporary increase in landings of small individuals. Theoretically in this model, a certain portion of these small individuals are distributed and consumed locally. But, in reality, such a sudden increase cannot be absorbed by local processors because the local market for this fish has just begun to develop. Therefore, a more stable supply is preferable.

Scenario 5 is an adaptive management scenario [35-38] that does not have severe difficulties in the initial period, effectively protects against the uncertain occurrence of strong year classes, and provides a more stable supply to the local market. In Japan, the large-scale purse seiners targeting the Pacific stock of chub mackerel (Scomber japonicus) have successfully recovered the resource by implementing a similar adaptive protection method of strong year classes since 2004 [1, 39]. This success in the chub mackerel fishery should make it easier to obtain consensus between hairtail trolling line fishers and purse seiners in the neighbouring prefectures. However, in this scenario, more than four strong year classes are required in 25 years. In other words, this 
scenario is heavily dependent on strong year classes. More than four occurrences of a strong year class in 25 years is a reasonable assumption [27], but it cannot be controlled artificially. Therefore, if a strong year class does not occur for a certain period (e.g. 5 years) and the stock level drops below a certain level (e.g. $3000 \mathrm{t}$ ), the management scenario should be changed to a more conservative one (e.g. 20\% decrease in FP in both fisheries). The pre-agreement of fishers to such a management shift is an important factor in dealing with the uncertainty of this scenario.

The price of fuel has fluctuated substantially in recent years. In the middle- and long-term, the price is expected to increase. In the sensitivity analysis, we assumed a $50 \%$ increase in fuel price, and found that scenario 5 with four strong year classes did not produce successful results. On the other hand, if the fuel price decreases by $50 \%$, more conservative and risk-aversive scenarios (e.g. scenario 4 with a $30 \%$ decrease in FP) might be feasible. Therefore, fuel cost fluctuations and technology development for fuel saving are important factors for the future of the hairtail trolling line fishery.

Setting a TAC and allocation of catch to each vessel or fisher as individual quotas (IQs) or individual transferable quotas (ITQs) is also a powerful tool for fisheries management [40-44]. As described earlier, TACs have been introduced for eight species in Japan. The IQ system has been officially introduced for red snow crab, southern bluefin tuna, and Atlantic bluefin tuna. Also, many autonomous IQ-equivalent measures have been introduced locally, for example, for sandfish [45], scallop [46], sea cucumber and chub mackerel [1], walleye pollock, horsehair crab, pink shrimp, Sakhalin surf clam, and finely striated buccinum. The national government of Japan recognizes the effectiveness of IQs as management tools, and has started discussions on the wider application of the IQ system to Japanese fisheries management, while stating that the ITQ system is not an appropriate option in the immediate future [47]. Therefore, we calculated the possible TAC management scenario for the hairtail stock. For example, if type-3 bait is used by trolling line fishers, the initial TAC for trolling line vessels and purse seiners can be set at 180 and $600 \mathrm{t} / \mathrm{year}$, respectively. In the year following a strong year class, $25 \mathrm{t}$ and $100 \mathrm{t}$ are added to the respective TACs. Then, all the targets would be achieved after three strong year classes, although this scenario has certain difficulties in the initial phase. The distribution of TAC to each vessel as IQs could be coordinated and decided upon within each sector. Implementation of TAC or IQs will be costly, but they represent effective and transparent management options for cross-jurisdictional stocks like hairtail.

In October 2014, we organized an open symposium to disseminate our results to the public. Representatives from the local high school in Usuki participated in this symposium, and made a presentation. These activities are important for wider support from the local community and to nurture future young fishers. Local and national governments also play important roles in helping to reach a consensus between trolling line fishers and purse seiners. Therefore, in October 2015, we organized a training course for Oita Prefecture government officers to use the Hairtail FSOM in local discussions with fishers. Also, we presented the results to the national government (Fisheries Agency) and recommended that they oversee its cross-prefectural coordination. Probably as a result of the above activities and intensive efforts made by local fishers and local/central government officers, a new agreement was made in spring 2016 among the trolling line fishers in Oita and Ehime Prefectures and purse seiners in Ehime Prefecture in order to decrease the FPs and protect spawners. This is not yet the perfect management scenario derived from the Hairtail FSOM, but it is a very big step in achieving this in the near future.

Several issues still need to be resolved. Securing successors for couple operations will be the next bottleneck because young women are generally reluctant to participate in the physically demanding operations on board (especially the sorting and weighing processes). Therefore, we have developed new fishing instruments that can be operated by a single person on board (Supplementary Figs. 2, 3 ). According to our experiments using the chartered boat, the total number of operations per day will be decreased by $20 \%$ when the single-person operation is introduced using these new instruments. At present, few fishers are showing interest in these new instruments, but if the resource recovers after implementing the above scenarios, then the average vessel could harvest enough fish to meet the annual income and VR targets to allow this to happen.

In the medium- to long-term, biological research is required to clarify the relationship between the ocean environment and the occurrence of strong year classes. The results of such studies should be incorporated into the Hairtail FSOM so that management plans can be drafted that will increase the resilience of this fishery to climate change. Also, an analysis of the international hairtail market is important. Currently, Korea imports medium-large hairtails from Japan as an expensive ingredient in a type of casserole (galchi jorim). Small hairtails are cheap and used for surimi or feed in Korea, so Japan does not export them to Korea at the moment. On the other hand, Japan imports medium-large hairtails from Africa or Central Asia as relatively cheap fish for supermarkets. Future changes in such international trade would have considerable impacts on the price of the Usuki hairtail. Finally, as illustrated in the sensitivity analysis, the fuel cost substantially affects the profitability of the fishery, and therefore, its management. Engineering innovations in the development of more efficient vessel engines, such as electronic or hybrid ones, or fuel cells, should be prioritized in integrated fisheries science in the near future. 
Acknowledgements We would like to thank the anonymous reviewers for their helpful comments on previous versions of this article. Furthermore, we would like to express our sincere thanks to the Usuki branch of the Oita FCA, Fisheries Research Division of the Oita Prefectural Agriculture, Forestry and Fisheries Research Center, the Ohta Engineering Federation, and Professor Tetsu Sato of Ehime University for helpful discussions and advice. This research received funding from the Marine Fisheries Research and Development Center, Japan Fisheries Research and Education Agency (Empirical Research Project for Marine Fisheries Resource Development: Hairtail Trolling Line Fishery around the Bungo Channel, Fiscal Year 2011-2013).

Open Access This article is distributed under the terms of the Creative Commons Attribution 4.0 International License (http://creativecommons.org/licenses/by/4.0/), which permits unrestricted use, distribution, and reproduction in any medium, provided you give appropriate credit to the original author(s) and the source, provide a link to the Creative Commons license, and indicate if changes were made.

\section{References}

1. Makino M (2011) Fisheries management in Japan: its institutional features and case studies, vol 34. Springer, Dordrecht

2. Lim CP, Matsuda Y, Shigemi Y (1995) Co-management in marine fisheries: the Japanese experience. Coast Manage 23(3):195-221

3. Jentoft S, McCay BJ, Wilson DC (1998) Social theory and fisheries co-management. Mar Policy 22(4):423-436

4. Makino M, Matsuda H (2005) Co-management in Japanese coastal fisheries: institutional features and transaction costs. Mar Policy 29(5):441-450

5. Uchida H, Makino M (2008) Japanese coastal fishery co-management: an overview. In: Townsend R, Shotton R, Uchida H (eds) Case studies in fisheries self-governance (FAO fisheries technical paper 504). FAO, Rome, pp 221-230

6. Gutiérrez NL, Hilborn R, Defeo O (2011) Leadership, social capital and incentives promote successful fisheries. Nature 470(7334):386-389

7. Sarker A, Ikeda T, Abe T, Inoue K (2015) Design principles for managing coastal fisheries commons in present-day Japan. Ecol Econ 117:32-38

8. Makino M, Sakamoto W (2003) History and international characteristics of the idea of fishery resource management in Japan. Nippon Suisan Gakkaishi 69:368-375 (in Japanese)

9. Keeney RL, Raiffa H (1993) Decisions with multiple objectives: preferences and value trade-offs. Cambridge University Press, Cambridge

10. Hilborn R (2007) Defining success in fisheries and conflicts in objectives. Mar Policy 31(2):153-158

11. Huang IB, Keisler J, Linkov I (2011) Multi-criteria decision analysis in environmental sciences: ten years of applications and trends. Sci Total Environ 409(19):3578-3594

12. Charles AT (1995) Fishery science: the study of fishery systems. Aquat Living Resour 8(3):233-239

13. Stephenson RL, Lane DE (1995) Fisheries management sciences: a plea for conceptual change. Can J Fish Aquat Sci 52(9):2051-2056

14. Makino M, Sakurai Y (2014) Towards the integrated research in fisheries science. Fish Sci 80:227-236

15. Esteves RA, Gelcich S (2015) Participative multi-criteria decision analysis in marine management and conservation: research progress and the challenge of integrating value judgements and uncertainty. Mar Policy 61:1-7
16. Clark CW (2010) Mathematical bioeconomics: the mathematics of conservation, vol 91. Wiley, Hoboken

17. Anderson LG, Seijo JC (2011) Bioeconomics of fisheries management. Wiley, Ames, IA

18. Ives MC, Scandol JP, Greenville J (2013) A bio-economic management strategy evaluation for a multi-species, multi-fleet fishery facing a world of uncertainty. Ecol Model 256:69-84

19. Pelletier D, Mahevas S, Drouineau H, Vermard Y, Thebaud O, Guyader O, Poussin B (2009) Evaluation of the bioeconomic sustainability of multi-species multi-fleet fisheries under a wide range of policy options using ISIS-Fish. Ecol Model 220(7):1013-1033

20. Marchal P, Vermard Y (2013) Evaluating deepwater fisheries management strategies using a mixed-fisheries and spatially explicit modelling framework. ICES J Mar Sci J Conseil 70(4):768-781

21. O'Neill MF, Leigh GM, Wang YG, Braccini JM, Ives MC (2014) Linking spatial stock dynamics and economics: evaluation of indicators and fishery management for the travelling eastern king prawn (Melicertus plebejus). ICES J Mar Sci J Conseil 71(7):1818-1834

22. Lang DJ, Wiek A, Bergmann M, Stauffacher M, Martens P, Moll P, Swilling M, Thomas CJ (2012) Transdisciplinary research in sustainability science: practice, principles, and challenges. Sustain Sci 7(Supplement1):25-43

23. Keeler BL, Chaplin-Kramer R, Guerry AD, Addison FE, Bettigole C, Burke IC, Gentry B, Chambliss L, Young C, Travis AJ, Darimont CT, Gordon DR, Hellmann J, Kareiva P, Monfort S, Olander L, Profeta T, Possingham HP, Slotterback C, Sterling E, Kicktin T, Vira B (2017) Society is ready for a new kind of science-is academia? Bioscience. doi:10.1093/biosci/bix051

24. Mauser W, Klepper G, Rice M, Schmalzbauer BS, Hackmann H, Leemans R, Moor H (2013) Transdisciplinary global change research: the co-creation of knowledge for sustainability. Curr Opin Environ Sustain 5:420-431

25. Oita Prefecture (2014) Local economic accounting of Oita Prefecture. Planning and Promotion Department of Oita Prefecture Government, Oita (in Japanese)

26. Ministry of Agriculture, Forestry and Fisheries (2015) Annual statistics of fisheries and aquaculture production. Norin-toukeikyokai, Tokyo (in Japanese)

27. Watari S, Tokumitsu S, Hirose T, Ogawa M, Makino M (2017) Stock structure and adaptive fisheries resource management of hairtail based on the seasonal brood around the Bungo Channel, Japan. Fish Sci. doi:10.1007/s12562-017-1140-y

28. Oda K, Hirota M (2013) Current status and evaluation of cutlass fish distribution system: study of how distribution channels for marine products should be in order to adapt to changes in the amount of resources. Japn J Fish Econ 57(2):1-14 (in Japanese)

29. Kunieda T (2015) Consumers behavior and psychological characteristics on hairtail. In: Horikawa $\mathrm{H}$ (ed) Business model for coastal fisheries. Tokai University Press, Tokyo, pp 109-120 (in Japanese)

30. Grafton RQ, Hilborn R, Squires D, Tait M, Williams M (2010) Handbook of marine fisheries conservation and management. Oxford University Press, Oxford

31. Charles AT (2008) Sustainable fishery systems. Wiley, Oxford

32. Hirose T, Sakurai M, Watari S, Ogawa M, Makino M (2017) Conservation of small size hairtail Trichiurus japonicus by large-sized artificial bait and the effect on stock and trolling line fishery. Fish Sci. doi:10.1007/s12562-017-1142-9

33. Ministry of Internal Affairs and Communication (2010) National survey of family income and expenditure. Nihon-toukei-kyokai, Tokyo (in Japanese) 
34. Statistic Bureau of Japan (2015) Annual report of consumer price index. Nihon-toukei-kyokai, Tokyo http://www.stat.go.jp/english/ index.htm (in English)

35. Walters C (1986) Adaptive management of renewable resources. Blackburn, New York

36. Berkes F, Colding J (2000) Rediscovery of traditional ecological knowledge as adaptive management. Ecol Appl 10(5):1251-1262

37. Matsuda H, Abrams PA (2004) Effects of predator prey interactions and adaptive change on sustainable yield. Can J Fish Aquat Sci 61(2):175-184

38. Armitage DR, Plummer R, Berkes F, Arthur RI, Charles AT, Davidson-Hunt IJ, Wollenberg EK (2008) Adaptive co-management for social-ecological complexity. Front Ecol Environ 7(2):95-102

39. Kawabata A, Watanabe C, Kamimura Y, Mito K (2015) Stock assessment of the chub mackerel Pacific stock in 2014. In: Report of the 2014 stock assessment for the fisheries resources around Japan. Fisheries Agency and Fisheries Research Agency, Yokohama, pp 137-172 http://abchan.job.affrc.go.jp/digests26/index. html (in Japanese)

40. Cancino JP, Uchida H, Wilen JE (2007) TURFs and ITQs: collective vs. individual decision making. Mar Resour Econ 22:391-406

41. Costello C, Gaines SD, Lynham J (2008) Can catch shares prevent fisheries collapse? Science 321(5896):1678-1681
42. Yagi N, Clark ML, Anderson LG, Arnason R, Metzner R (2012) Applicability of individual transferable quotas (ITQs) in Japanese fisheries: a comparison of rights-based fisheries management in Iceland, Japan, and United States. Mar Policy 36(1):241-245

43. León R, Gardner C, van Putten I, Hartmann K (2015) Changes in the lease and permanent sale quota markets of a rock lobster fishery in response to stock abundance. ICES J Mar Sci J Conseil $72: 1555-1564$

44. Holzer J (2015) Property rights and choice: the case of the fishery. Am J Agric Econ 97:1175-1191

45. Tamaki Y (2004) Fisheries management of sandfish in Akita Prefecture. In: Proceedings of International Institute of Fisheries Economics and Trade (IIFET) 2004, Tokyo

46. Hirota M, Kosaka Y (2010) The TASC (total allowable scallop culture) in Japan: an approach for the issue on the overproduction in Yezo giant scallop cultivation in Mutsu Bay. In: Proceedings of PICES (North Pacific Marine Science Organization) Annual meeting October 23-November 12010 , Portland

47. Fisheries Agency (2014) The main points of the report by the Ad Hoc Task Force on Fisheries Resource Management http:// www.jfa.maff.go.jp/j/kanri/other/pdf/unofficial_translation.pdf (in Japanese) 